\title{
Canadian Institutes of Health Research proposes major initiative on Alzheimer disease in step toward national dementia strategy
}

$\mathrm{T}$ The Canadian Institutes of Health Research (CIHR) is leading a new international effort to further Alzheimer disease research, with a focus on early detection and prevention.

"What we are trying to do is mobilize international interest for a collaborative initiative on Alzheimer's disease research, but it's in the early days," says CIHR President Dr. Alain Beaudet.

The CIHR has decided to focus on Alzheimer disease for several reasons, says Rémi Quirion, executive director of the International Collaborative Research Strategy for Alzheimer's Disease project. Unlike people suffering from many other common diseases such as cancer, diabetes or heart disease - people with Alzheimer disease have no treatment options. Plus the CIHR had already identified aging as a critical topic affecting health care in Canada, and Alzheimer disease is a major problem associated with aging. It was also necessary for Canada to invest in Alzheimer disease research to gain credibility in this area around the world, says Quirion.

"It is always a bit challenging when you focus on one disease, and it is always in the end a question of budget," says Quirion. "Overall, almost everyone in health care would recognize that this is a major issue."

It may be in its infancy, but the initiative is already earning praise.

"It really has a head of steam," says Scott Dudgeon, chief executive officer of the Alzheimer Society of Canada. "They have some dedicated resources for doing this and it looks very promising."

On Mar. 15 and 16, the CIHR and the European Research Area-Canada Initiative held a workshop on Alzheimer disease in Prague, Czech Republic. The meeting marked the official launch of the CIHR initiative. Rep-

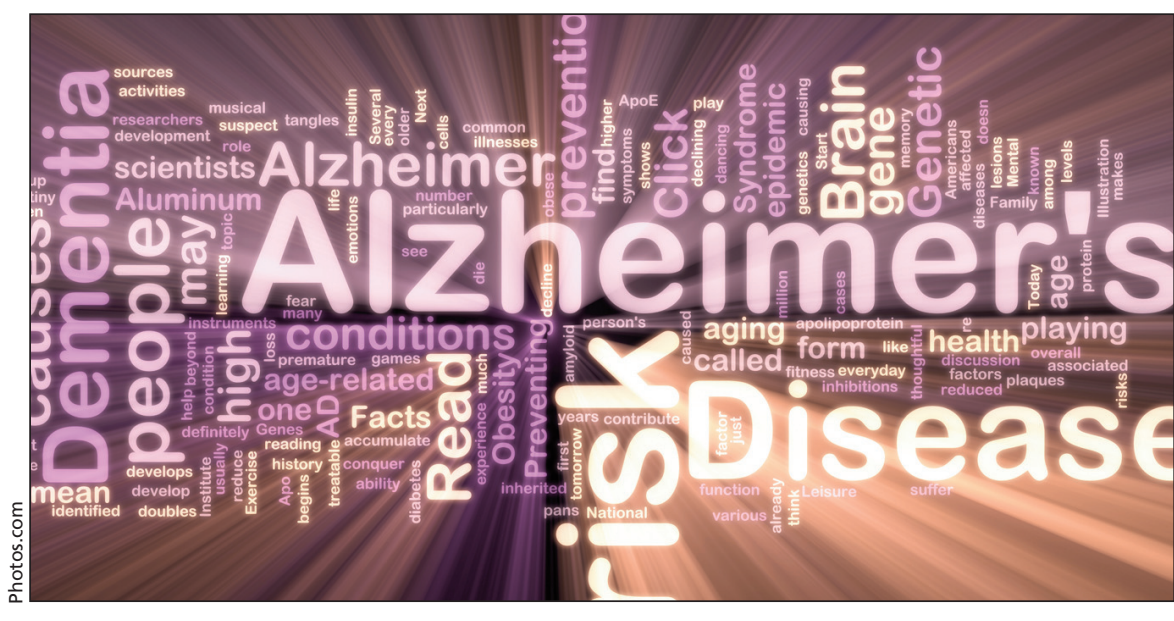

The Alzheimer Society of Canada estimates that 500000 Canadians have Alzheimer disease or a related dementia, with some 71000 of those under age 65 .

resentatives from Canada, France, Germany, Italy and the United Kingdom attended the workshop, during which they discussed 4 research areas: biomarkers, animal models, innovative therapeutic strategies and prevention. The major themes that emerged from discussions were early diagnosis and early intervention.

"For Alzheimer's disease, it's early, early, early," says Beaudet. "It's like location, location, location in real estate."

Dementia researchers don't know how early Alzheimer disease can be detected. Clinical trials to test means of detecting and preventing the disease have thus far proven disappointing, Beaudet says, because the participants were treated too late. Treatment has little effect after a patient's brain has suffered substantial neurological degeneration. Researchers agree that new and better clinical trials are needed, but the high cost of such studies, which can last as long as 7 years, is a major impediment.

"No one country can afford to do these larger prevention studies alone. ... We are all in this together and people know that," says Dr. Serge Gau- thier, director of the Alzheimer's Disease Research Unit at the McGill Centre for Studies in Aging in Verdun, Quebec. "The payoff will be enormous if we can delay by 5 to 7 years the onset of Alzheimer."

In 2007/08, the Canadian government, through CIHR, invested about \$21 million in Alzheimer disease research, the bulk going toward biomedical research. Canadian researchers say much more is needed and point to other countries as models - especially France. In 2008, French Prime Minister Nicolas Sarkozy launched the world's first comprehensive plan to combat Alzheimer disease, committing $€ 1.6$ billion ( $\$ 2.5$ billion) to the cause.

It is this type of comprehensive approach - encompassing not only research but such things as long-term support and community services for caregivers - that Dudgeon would like to see implemented in Canada. "I don't think Canadians expect Canada to be the last country to have a dementia strategy," he says. "I think we need a national program. The federal government is responsible for research, but in 
terms of diagnosis and treatment, those areas are of provincial responsibility. The response from the provinces has been spotty."

Dudgeon has nothing but praise, however, for Canadian dementia researchers, whom he says are "certainly punching above their weight class." Beaudet agrees, and says Canadian expertise in Alzheimer disease research is something worth sharing -and expanding.

"The other idea is to showcase our talent internationally in this area because we have it," says Beaudet, who once worked for the Montréal Neurological Institute in Montréal, Quebec. "It will also be of immense benefit to our scientists to be able to tap into the world's resources."

Over the next 5 years, Beaudet hopes to build upon existing international collaborations and encourage innovation in key research areas, such as prevention. He would also like to have further collaborative discussions with the United States.

This fall, the CIHR, in conjunction with France and the province of Quebec, will launch a request for applications from multidisciplinary groups needing funding for "large, innovative, cutting-edge" Alzheimer disease projects. Annual contributions will come from CIHR (\$600 000), Quebec (\$800 000) and France (€700 000, or $\$ 1.1$ million) over a 3-year period. According to a May 21 briefing note on the Prague meeting, the ultimate goal is for Canada and Europe to develop a joint request-for-applications process, with annual contributions of $\$ 5$ million over 5 years from CIHR, the United Kingdom and France.

International collaboration is vital to learn more about Alzheimer disease and how to treat it, says Beaudet. "You need some competition in research, but there are things that working together would allow us all to do considerably faster. ... With an aging population, dementia will be a huge burden on the population as time goes by. The cost will be unbelievable 15 to 20 years from now." - Roger Collier, CMAJ

DOI:10.1503/cmaj.091124 